\title{
XII.
}

\section{Aus dem Leben des Cynikers Diogenes.}

\section{Von \\ Hermann Diels in Berlin.}

„Aus der Jugendzeit des Diogenes wissen wir nichts weiter als dass er aus Sinope gebürtig war, dass sein Vater Hikesias Wechselgeschäfte trieb und den Sohn früh zu demselben Geschäfte anhielt. Der Vater scheute sich nicht neben dem Geschäfte des Wechsless auch das eines Falschmünzers zu betreiben und den Sohn in dasselbe bei Zeiten einzuweihen. Diesem scheint nun freilich gleich anfangs nicht ganz wohl zu Mute gewesen zu sein bei dieser geheimen Hausmünze, aber er beruhigte sich darüber und hatte später sogar die Schwäche, sein Gewissen auf eine wahrhaft perfide Weise durch jesuitische Auslegung eines Götterausspruchs zum Schweigen zu bringen. Als fertiger Falschmünzer kam er nämlich auch nach Delphi in den Tempel des Apollon. Dort hätte er sich nun, als er in den Vortempel trat und die Sprūche überlas, die dort standen, an den klaren Spruch: „Erkenne

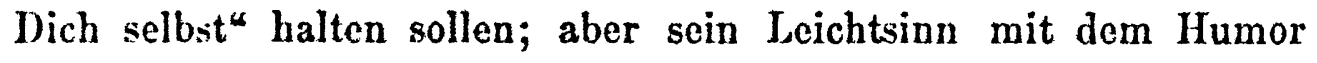
gepaart, der ihm ron jeher eigen war, haftete mit Vergnïgen auf dem doppelsinnigen Spruche „Auf die Münze präg' den eignen Stempel “. Er überredete sich der Spruch enthalte eine offenbaro Billigung seines Falschmünzergeschäftes und so durch seine falschmünzerische Interpretation des Götterspruches scheinbar beruhigt, kam er wieder nach Sinope und münzte mit seinem Vater fort, bis die Strafe über beide hereinbrach. Der Vater starb in Geraugnis, der Sohn suchte das Weite; die Acht ward über dem Fliohenden ausgesprochen, der sich nach Athen wendete." 
Also lautet ungefïhr der Roman, den Göttling, der Biograph des Cynikers '), von dessen Jugendleben zu berichten weiss. Aehnlich, nur etwas confuser erzählt Laertios Diogenes, und ähnliches mïssen auch bereits die alexandrinischen Litteraten gefabelt haben.

Nun ist es ja heutzutage unzweifelhaft, dass weder im Tempel zu Delphi noch zu Delos der Spruch rapxyápaรoy tì vóucoux gestanden haben kann, da er in seiner eigentlichen Bedeutung sinnlos und in übertragener jedenfalls für die heiligen Stätten, die Schützer und Bewahrer des vóuss, ungeeignet ist, ganz abgesehen davon, dass eine solche Sentenz vor dem fünften Jahrhunderte überhaupt undenkbar wäre und ganz abgesehen von den metrischen Spielereien, die Göttling ${ }^{2}$ ), nicht zu seinem Ruhme, mit den angeblich Pythischen Sprüchen getrieben hat. Aber der. Kern der Erzählung, dass der Cyniker in seiner Jugend Falschmünzer gewesen sei, wird trotz der scharfsinnigen Bedenken, die bereits Steinhart ${ }^{3}$ ) dagegen vorgebracht hatte, noch immer aufrecht erhalten; wie ich glaube, mit Unrecht.

Zunächst ist es lediglich eine Vermutung Göttlings, dass jener Falschmünzerspruch zu den altberühmten, in der Vorhalle zu Delphi angeschriebenen, gehöre. Vielmehr' behauptet die alexandrinische Biographie, von der Diokles (Laertios), Julian und. Suidas abhängig sind, ausdrücklich, der Orakelspruch sei dem Diogenes persönlich 'auf seine Anfrage erteilt worden. Diokles bringt nun in dem Wirrwar streitiger Nachrichten über die angebliche Falschmünzerei des Diogenes oder seines Vaters, die wertvolle Notiz, dass Diogenes sich selbst in seinem Dialoge Pordalis ${ }^{4}$ ) zur Falschmün-

1) Diogenes der Cyniker oder die Philosophie des griechischen Proletariats in Abhandlungen aus dem class. Altertum I (Halle 1851) $251 \mathrm{ff}$.

2) a. O. S. $221 \mathrm{ff}$.

3) Ersch u. Gruber-Encyclop. S. I, B. XXV (1834) S. 302.

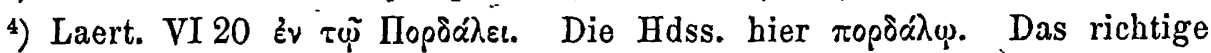
Wort gibt der Katalog der Diogenischen Schriften zweimal $\S 80$ als Mápo $\alpha \lambda_{l s}$,

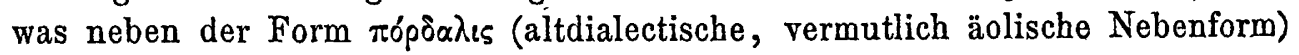
stehen bleiben kann. Welche Symbolik Diogenes an den Namen der gefleckten Bestie geknüpft hat, weiss ich nicht, aber dass der Titel wirklich diese

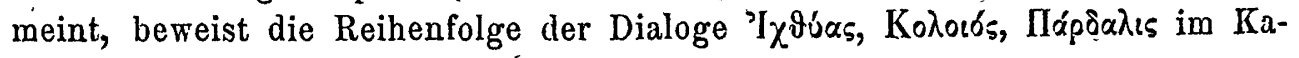
taloge. 


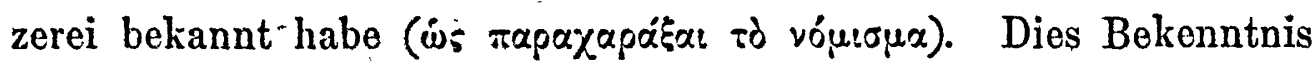
scheint mir eine andere als die wörtliche Erklärung nicht nur zu gestatten, sondern zu fordern.

Verstehen wir nemlich dies Sündenbekenntnis wörtlich, so mag ja das Prahlen mit Dingen, die nach der gewöhnlichen Moral infam, nach der cynischen Adiaphora sind, der Persönlichkeit des Diogenes zugetraut werden, aber unverständlich wäre dann die Verbindung mit dem delphischen Gotte, zu der ja doch dieso in Sinope begangenen Jugendsünde gar keine Veranlassung gab, in der antiken Biographik. Wir werden daher jene Selbstbezichtigung etwas anders verstehen müssen.

Wie Sokrates sich als Sohn einer Hebamme der Maicutik rühmte und zur Bestätigung seines Berufes sich auf den delphischen Gott berief, der ihn durch das Orakel des Chairephon wie

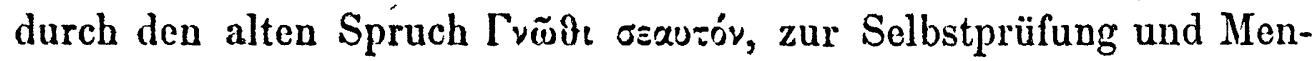
schenprüfung autorisirt habe, so wird Diogenes, die Caricatur des Sokrates, sich mit Beziehung auf den Beruf seines Vaters, des Trapeziten Hikesias mit seiner Falschmünzerei aufgespielt haben, die er im Auftrage des Pythischen Gottes treiben müsse. Er wird es als seine heilige Aufgabe hingestellt haben, das Naturgesetz an die Stelle der Menschensatzung, das Wissen an die Stelle des Glaubens, die Philosophic an die Stelle der traditionellen Bildung $z \mathrm{u}$ setzen, mit

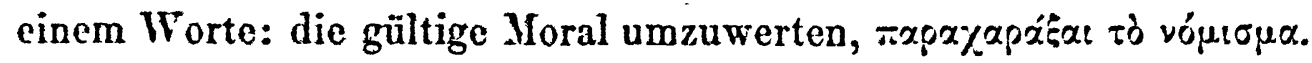
Das ist das Schlagwort des Cynismus, ja man kann sagen der ganzen Sokratik. So hat das Wort schon Julian verstanden und mit Sokrates in Beziehung gesetzt ${ }^{5}$ ), und offenbar schwebte es auch

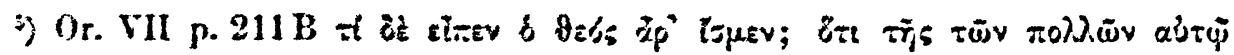

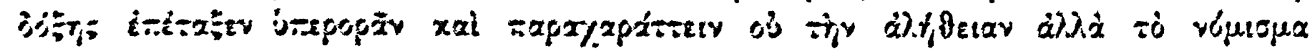
$(=-\dot{z}$ vetsokrz p. 211 c) und VI p. 188D f. vergleicht er in dieser Beziehung die Anschaung des Sokrates (Kriton p. 44c). Auch die alten Biographen batten teilweise noch die Abnung des wirklichen Sachverhaltes Laert. VI 20

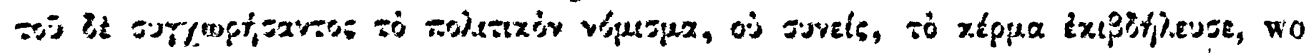
das Jiverstandnis dem Cyniker selbst in die Schuhe geschoben wird, einfaltiger Weise. Verständig dagegen biokles (denn seine Art spricht sich hicr aus)

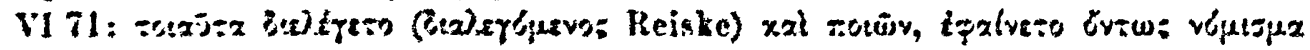

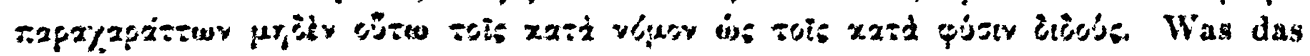
Wort ixpxyzaziesetv betrift, so beisst es allerdings gexöhnlich die Jünzo fäl- 
316 Hermann Diels, Aus dem Leben des Cynikers Diogenes.

Friedrich Nietzsche noch von seinen Laertiosstudien her vor der Seele, als er die grosse moralische Revolution, die nach seiner Meinung durch Sokrates und die Juden hervorgerufen wórden ist, als „Umwertung der Moral“ , bezeichnete, die nun seinerseits wieder auf die richtige Währung ,jenseits von Gut und Böse" zurückgeprägt werden müsse.

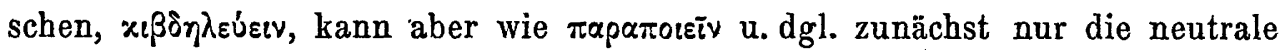

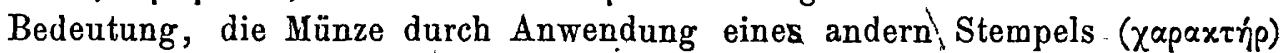
verändern, haben (vgl. Percy Gardner Classical Review VII, 1893, S. $437 \mathrm{ff}$.). 